Article

\title{
Measuring Knowledge of Words with Multiple Meanings
}

\author{
Yuko Hoshino \\ Tokyo Fuji University \\ doi: http://dx.doi.org/10.7820/vli.v04.1.hoshino
}

\begin{abstract}
When reading or listening to English, we encounter many words, most of which are high-frequency, polysemous words. Due to their polysemous nature, not knowing one particular meaning of a high-frequency word may prevent learners from understanding the wider contexts. Therefore, it is necessary to know whether learners have knowledge of multiple meanings of one word; however, there is no universally accepted way to measure knowledge of words with multiple meanings. With this in mind, the current paper looks at the difficulties of measuring learners' knowledge of polysemous words and describes ongoing research on this topic.
\end{abstract}

\section{Introduction}

When reading or listening to English we encounter many words, most of which are high-frequency words. For example, Adolphs and Schmitt (2003) found that 209 word families cover more than $80 \%$ of spoken vocabulary and 1000 individual word forms cover $89.25 \%$ of the spoken British National Corpus. In addition, when we turn our attention to written texts, which generally include more low-frequency words than spoken texts, Nation (2006) summarized that the most frequent 1000 word families cover $78-81 \%$ of the total word count. Hence, highfrequency words are important for understanding English.

It is also generally understood that vocabulary knowledge correlates with comprehension of texts, as shown by Jeon and Yamashita's (2014) meta-analysis of 31 studies which yielded a correlation coefficient of $r=.79$ [.69-86]. This relationship has also been presented by investigations looking at the connection between reading comprehension and vocabulary breadth (e.g., Iso \& Aizawa, 2010; Laufer \& Ravenhorst-Kalovski, 2010), which refers to how many words learners know (i.e., knowing many low-frequency words means they are better learners). However, the lexical coverage of low-frequency words is much lower than that of high-frequency words. Thus, it is possible that knowing high-frequency words is equally as important as knowing low-frequency words when it comes to comprehension of texts. High-frequency words often have more than one meaning, so not knowing one particular meaning of a high-frequency word possibly prevents learners from understanding the text. In order to investigate this issue, it is necessary to know whether learners have knowledge of multiple meanings of one word, however, there is no universal way to measure knowledge of words with 
multiple meanings. With this in mind, the current paper describes ongoing research into measuring learners' knowledge of multiple meanings of one word.

\section{Difficulty in Measuring Knowledge of Words with Multiple Meanings}

The importance of knowing high-frequency words, which often have more than one meaning, is widely understood, but much of the existing research has focused on how effectively learners acquire low-frequent new words. Learning new words is different from learning new senses of old words. When learners first try to acquire a new word, both the word form and its meaning are new, but when they learn a new meaning of a known word, "people add to their already extensive repertoires of words for which they know multiple different senses" (Rodd, Gaskell, \& Marslen-Wilson, 2002, p. 1096). Thus, learning a new meaning of a previously known word requires restructuring of one's existing mental lexicon that contains the word. This presents a number of difficulties when attempting to determine whether learners have succeeded in acquiring new meanings or not.

First is ambiguity resolution. When a word has more than one meaning, and there is a target meaning the researcher wants to measure, it is necessary to distinguish the target meaning from other meanings. One solution is to provide context. For example, Khanna and Cortese (2011), who investigated the Age of Acquisition (AoA) of ambiguous and polysemous words, presented the target word duck as follows:

duck

To bend down

By presenting the definition "to bend down," the researchers distinguished the target meaning from the meaning of $d u c k$ as a bird. Degani and Tokowicz (2013) also provided minimum contexts for target words (e.g., rose: red rose and rose above). However, the problem remains as to whether these minimum contexts provide sufficient cues for the learners to use when their knowledge is being assessed. Also, when longer texts are presented in order to better resolve the ambiguity, the amount of information the text contains differs by context, which produces another problem.

The second difficulty pertains to grammatical knowledge. When a word's meaning changes, often its grammatical usage changes as well. For example: time can be used as a noun or as a verb, both relating "what is measured in minutes, hours, days." Should we differentiate time as a noun from time as a verb when we want to measure knowledge of multiple meanings of this word? A word like present makes this problem more complicated. Present has two meanings: existing or happening now and gift. Present meaning "now" often takes the adjectival form; however, it can also be used as a noun. On the other hand, present meaning "gift" is often used as a noun but can also be used as a verb. This change of word class makes it difficult to separate grammatical knowledge and knowledge about multiple meanings. Moreover, with verbs tending to be more abstract and ambiguous than nouns (Crossley, Subtirelu, \& Salsbury, 2013), it is especially 
important to consider this difference between word classes. There are also cases where usage differs between two or more meanings within the same word class. For example, admit has two meanings (enter and confess), but admit meaning "enter" takes a direct object after the main verb whereas admit meaning "confess" takes a full clause (Uçkun, 2012). Therefore it seems contextual meaning and grammatical structure help determine the intended meaning of words with multiple meanings.

The third difficulty is the relationship between meanings. Words with multiple meanings can be divided into two types: polysemous and homonymous. The meanings of polysemous words are somewhat related to each other, whereas those of homonymous words are distinct (e.g., Rodd et al., 2002). Homonymy is more prominent because the meanings are usually completely different from each other. On the other hand, polysemy does not usually stand out. For example, some English textbooks for junior high schools in Japan have separate listings for new meanings of previously learned homonymous words. Also, they include notes about these words and try to draw learners' attention to them. However, as written above, textbook writers tend not to turn their attention to polysemy probably because of the semantic relatedness between meanings. Rodd et al.'s (2012) L1 study showed that when the novel meaning and the existing meaning are closely related, the recall of novel meanings is significantly better. Yet it is not yet known whether polysemy is more effectively acquired than homonymy for L2 learners. Even within polysemy, the distance between the meanings differs. One meaning within polysemy is the prototypical meaning, and the others are extended meanings, the degree of which differs. In other words, some meanings are rather strongly related, and learners can easily infer the extended meaning from the prototypical one. However, when their relationship is too strong, we might wonder whether these meanings are two distinct meanings or not. For example, Degani and Tokowicz (2013) asked participants to rate the similarity between the meanings of one word. They used a 7-point scale, and some meanings were rated as not similar (e.g., 1.15 for red rose and rose above), but others were similar (e.g., 5.30 for cotton dress and cotton thread). The dictionary entries for cotton treat these two meanings as separate, but

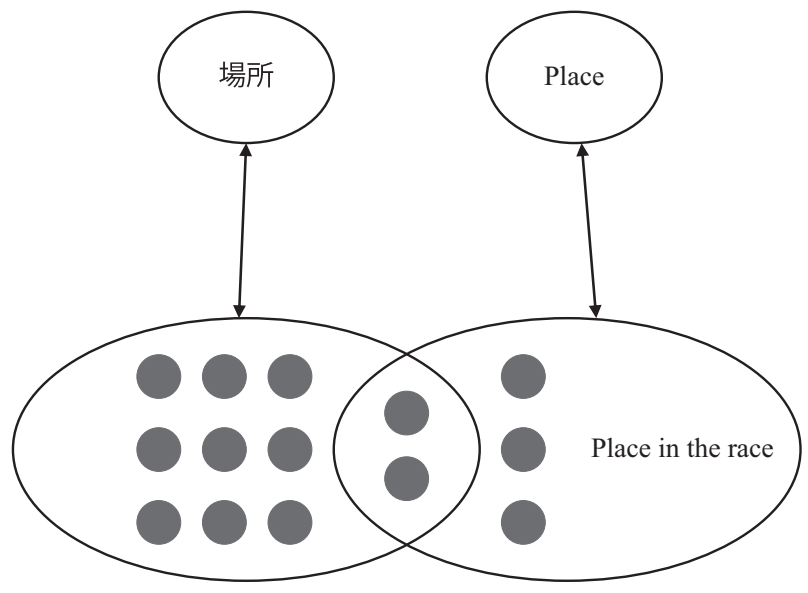

Figure 1. Sense Model (modified from Finkbeiner et al., 2004). 
it is not yet known whether teachers should teach these meanings one by one or whether learners will automatically learn the extended meaning (cotton thread) when they learn the prototypical one (cotton dress).

Another problem related to meaning is cross-language differences. According to the Sense Model by Finkbeiner, Forster, Nicol, and Nakamura (2004), shown in Figure 1, several senses (small black circles in the figure) belong to one word each in the mental lexicon. Some of the senses are shared by two languages, and other senses are language-unique. For example, both basho in Japanese and place in English refer to "place as a space." Hence, basho and place are often paired and memorized in the beginning stage of learning, according to the equivalence hypothesis (Ringbom, 1987). However, pairing only one L1 word and one L2 word is insufficient because L1 and L2 concepts are not equal and some senses are peculiar to one language (Finkbeiner et al., 2004). For example, place has the concept of "place in the race," which has a different Japanese translation, jun'i. Therefore, when developing a test to measure knowledge of words with multiple meanings, it is desirable to measure the developmental change in learners' mental lexicon.

\section{Summary of Hoshino (in Press)}

Considering some of the abovementioned difficulties, Hoshino (in press) compared six types of test for multiple meanings of basic words to identify the best test from the viewpoints of difficulty, reliability, discriminability, and correlation coefficients. About half of the participants took tests that presented the target words in sentences, and the remaining participants took tests that presented the target words in collocations. Seven basic verbs (break, get, have, leave, make, see, and take) were the target words, and there were six types of measurement, as Table 1 shows.

In the selection test, participants chose the correct expressions of the target verbs out of eight possible answers. Table 2 shows the selection test in sentential context. The participants read the sentences, decided whether the underlined expressions were correct English expressions or not, and marked their judgment as correct $(\bigcirc)$ or incorrect $(\times)$ in the right column. The number of correct expressions was six for all the target verbs, but the participants were not notified how many correct answers there would be. The learners who were tested in collocation were presented only the underlined contexts.

Table 1. Six Types of Measurements in Hoshino (in press)

\begin{tabular}{llc}
\hline & Form (within-subject factor) & Context (between-subject factor) \\
\hline 1 & Selection & Sentence \\
2 & Translation & Sentence \\
3 & Pairing & Sentence \\
4 & Selection & Collocation \\
5 & Translation & Collocation \\
6 & Pairing & Collocation \\
\hline
\end{tabular}

Vocabulary Learning and Instruction, 4 (1), 58-65. 
Table 2. The Selection Test in Sentential Context in Hoshino (in press)

\begin{tabular}{|c|c|c|}
\hline & & $O / \times$ \\
\hline 1 & He broke the secret to the public. & \\
\hline 2 & They broke the law by not stopping at a red light. & \\
\hline 3 & They broke the scene in their movies. & \\
\hline 4 & He broke the end of the story. & \\
\hline 5 & He broke the skin on his legs. & \\
\hline 6 & She broke the news to me. & \\
\hline 7 & The stone broke the surface of the water. & \\
\hline 8 & I'm not going to break my promise to her. & \\
\hline
\end{tabular}

Table 3. The Translation Test in Sentential Context in Hoshino (in press)

\begin{tabular}{lll}
\hline 1 & He broke the secret to the public. & Write translation \\
2 & They broke the law by not stopping at a red light. \\
3 & He broke the skin on his legs. \\
4 & She broke the news to me. \\
5 & The stone broke the surface of the water. \\
6 & I'm not going to break my promise to her. \\
\hline
\end{tabular}

The translation test is presented in Table 3. The material was the same as the selection test except for the distractors (i.e., Nos. 3 and 4 in Table 2). Only the correct expressions were presented, and the participants were asked to write the translations of the underlined expressions. Similar to the selection test, only the underlined contexts were shown to the participants who were tested in the collocation condition.

The pairing test was conducted with the same target materials as the translation test. The participants were required to find three pairs of the target expressions with the same meaning. Each target verb had three pairs (i.e., Nos. 1 and 4, Nos. 2 and 6, and Nos. 3 and 5 have the same meaning in Table 3).

Results showed that of the six measurements, the translation test in sentential context had the highest reliability and discriminability. The translation test had significant correlation coefficients with the vocabulary size test and the reading test, but the selection test and the pairing test did not, also their correlation coefficients were weak or even negative. Between the two translation tests with different length of contexts (collocation or sentence), the test in sentential context had a higher correlation than the one in collocation. Considering that the construct measured by the vocabulary size test and the reading tests was at least somewhat related with the construct that the test for words with multiple meanings was designed to measure, the translation test in sentential context was the better test among the six tests in Hoshino (in press). However, questions remain. How long should the sentence be? What information should be included in it? Are there any other, better tests? 


\section{Other Possible Measurement Methods}

Hoshino (in press) did not use the isolation test, an isolation test is one of the possible methods of measuring multiple meanings. An example is as shown below.

Write as many meanings of each word as possible.

1. present

2. take

$\begin{array}{ll}( & ) \\ ( & )\end{array}$

)

This method is used especially when researchers want to make a list of polysemy meanings (e.g., Durkin \& Manning, 1989; Tagashira, Sakata, Hoshino, \& Mochizuki, 2014). Rodd et al. (2012) used a similar method. They presented the target words in isolation and asked the participants to write the properties of the novel meanings they had learned. When at least one of the properties they wrote was correct, the response was regarded as correct. However, producing as many meanings as possible without any cues is difficult even for advanced L2 users. For example, in Tagashira et al.'s study above, two English teachers produced answers to the 68 words with multiple meanings, but they answered at most five meanings per word. The average number of answers per word was only two or three, so it is difficult to grasp the development of the mental lexicon by this measure only. Furthermore, there is the problem of loan words. Japanese has a lot of loan words, and this becomes a problem when using this measure. For example, program has several meanings in English, and these meanings are often used in Japanese as プログラム [puroguramu]. However, プログラム has different meanings, as in a computer program or concert program. Hence, if the participants write only プログラム, we do not know which meaning of program they intend.

Another measure, which presents the target words in isolation, is the translation recognition test. In this test, researchers present the target word first and then its target meaning to the participants, and participants judge whether the second word is the first word's correct meaning or not as quickly and accurately as possible. The translation recognition test does not require participants to produce the translation, so it is more suitable for investigating the developmental stage of acquisition or beginning learners (Sunderman, 2014).

\section{Conclusion}

So far, several measurements have been introduced, but we still do not know which measurement is better than others and which should be used in which circumstances. Making a valid test for knowledge of multiple meanings will deepen our understanding of learners' mental lexicon, so the further research is necessary for this topic. 


\section{References}

Adolphs, S., \& Schmitt, N. (2003). Lexical coverage of spoken discourse. Applied Linguistics, 24, 425-438. doi:10.1093/applin/24.4.425

Crossley, S. A., Subtirelu, N., \& Salsbury, T. (2013). Frequency effects or context effects in second language word learning. Studies in Second Language Acquisition, 35, 727-755. doi:10.1017/S0272263113000375

Degani, T., \& Tokowicz, N. (2013). Cross-language influences: Translation status affects intraword sense relatedness. Memory \& Cognition, 41, 1046-1064. doi:10.3758/s13421-013-0322-9

Durkin, K., \& Manning, J. (1989). Polysemy and the subjective lexicon: Semantic relatedness and the salience of intraword senses. Journal of Psycholinguistic Research, 18, 577-612. doi:10.1007/BF01067161

Finkbeiner, M., Forster, K., Nicol, J., \& Nakamura, K. (2004). The role of polysemy in masked semantic and translation priming. Journal of Memory and Language, 51(1), 1-22. doi:10.1016/j.jml.2004.01.004

Hoshino, Y. (in press). Development of a test to measure knowledge regarding multiple meanings of basic words. JLTA Journal, 18.

Iso, T., \& Aizawa, K. (2010). Toward better interpretations of vocabulary size test scores for estimating reading proficiency. Annual Review of English Language Education in Japan, 21, 141-150.

Jeon, E. H., \& Yamashita, J. (2014). L2 reading comprehension and its correlates: A meta-analysis. Language Learning, 64, 160-212. doi:10.1111/lang.12034

Khanna, M. M., \& Cortese, M. J. (2011). Age of acquisition estimates for 1,208 ambiguous and polysemous words. Behavior Research Methods, 43(1), 89-96. doi:10.3758/s13428-010-0027-y

Laufer, B., \& Ravenhorst-Kalovski, G. C. (2010). Lexical threshold revisited: Lexical text coverage, learners' vocabulary size and reading comprehension. Reading in a Foreign Language, 22, 15-30.

Nation, I. S. P. (2006). How large a vocabulary is needed for reading and listening? Canadian Modern Language Review, 63(1), 59-82. doi:10.3138/cmlr.63.1.59

Ringbom, H. (1987). The role of first language in the second language learning. Clevedon/Philadelphia; Multilingual Matters.

Rodd, J., Gaskell, G., \& Marslen-Wilson, W. (2002). Making sense of semantic ambiguity: Semantic competition in lexical access. Journal of Memory and Language, 46, 245-266. doi:10.1006/jmla.2001.2810

Rodd, J. M., Berriman, R., Landau, M., Lee, T., Ho, C., Gaskell, M. G., \& Davis, M. H. (2012). Learning new meanings for old words: Effects of semantic relatedness. Memory \& Cognition, 40, 1095-1108. doi:10.3758/s13421-012-0 209-1

Sunderman, G. (2014). Translation recognition tasks. In J. Jegerski \& B. van Patten (Eds.), Research methods in second language psycholinguistics (pp. 185-211). New York, NY: Routledge. 
Tagashira, K., Sakata, N., Hoshino, Y., \& Mochizuki, M. (2014, March). Nihonjin EFL gakusyusha no tagigo ni taisuru honyakugo database [Translation database of polysemy by Japanese EFL learners]. Paper presented at the Fourth Joint Conference on English Vocabulary and Lexicography Program. Chiba: Reitaku University.

Uçkun, B. (2012). Awareness of verb subcategorization probabilities with polysemous verbs: The second language situation. System, 40, 360-375. doi:10.1016/j.system.2012.08.002 